\title{
TROPICAL DISEASES AND PUBLIC HEALTH
}

STUDIES ON MALARIA CONTROL V. THE IMPORTANCE OF DISINFECTING ALL CASES TREATED AS A FACTOR IN MALARIA CONTROL IN A LOCALITY OF GREAT PREVALENCE*

BY C. C. BASS, M.D., New Orleans, La.

The object of this paper is to call attention to the importance of disinfecting all cases of malaria treated by physicians in localities where the disease prevails to great extent and also to point out some of the causes of failure to do this.

Thorough disinfection of a case of malaria may be beneficial, first, to the patient by curing him and preventing relapse; and, second, to the community, including especially those who live in close association with him, by preventing transmission of the infection to them. In a locality where malaria does not prevail to any considerable extent and therefore is not transmitted, thorough treatment benefits the patient only. On the other hand, in a community where the disease prevails and favorable conditions for transmission exist, it is important that he be disinfected for the sake of others as well as himself.

The importance of disinfecting malaria cases as a factor in the problem of malaria control has been more or less overlooked by most of us, but in some instances it has been recognized. Among those in this country who have advanced and supported this idea should be mentioned Seale Harris. With reference to this particular phase of malaria control, he said:1

"It is not my intention to suggest any less vigilance in destroying the Anopheles mosquitor's and their breeding places, and $I$ would urge that

*From the Department of Experimental Medicine, Tulane Medical College, New Orleans, La.

This is one of a series of papers to be published, based largely or entirely upon malaria control work conducted jointly by the International Health Board and the Mississippi State Board of Health.

Read before Mississippi State Medical Association, Hattiesburg, May 14, 1919. these measures be employed to the fullest extent possible. I do maintain, however, that the most important and the most practical measure, at this time, in the crusade against malaria is the radieal cure of those harboring parasites, be. cause every patient cured means one less focus of infection."

Henson has been another advocate of the importance of disinfecting malaria carriers as a means of control. As he says :-

"Literature on the prophylaxis of malarial fevers teems with articles concerning the eradjcation of the mosquito, and means to prevent this insect from giving malaria to men, while little is said as to preventing naan from giving malaria to the mostuito."

\section{UNCURED CASES THE CHIEF SOURCE OF TRANSMISSION}

The chief source of transmission of malaria is malaria carriers who have not been disinfected following attacks of malaria. The usual treatment, whether prescribed by doctors or otherwise, does not disinfect any considerable proportion of the cases treated. Few of the general run of cases of malaria are actually disinfected ly treatment. The firequency of malaria relapse shows conelusively that the usual treatment is very inefficient. In a carefill study of a group of 3,815 persons living in Sunflower County, Mississippi, in $1918, "$ made with the object of determining the frequency of malaria relapse, it appears that from 50.77 to $68.86 \%$ of all persons who have attacks of malaria during a given year have relapses and not new infections. This is an area of great prevalence in the Mississippi Delta, and it is very probable that the frequency of relapse indicated corresponds fairly well to what occurs in other malarious sections.

If more than $50 \mathrm{c} /$ of the cases of malaria that occur during a year are relapses, it is very apparent that if all cases of malaria were disinfected during a given year the number of malaria carriers and sources of infection during the following year would be reduced at least $50 \%$. Thorough disinfection of all infected persons in a given locality would result not only in a reduction of $50 \%$ in the number of cases of malaria that occur by prevent- 
ing relapses, but it would also result in an equal reduction, or in fact absence of new cases of malaria that would occur during the following year because of the absence of malaria carriers as a source of infection. Theoretically, there should be no malaria during a year following the disinfection of all persons who have malaria in a given locality. Such a result has not been accomplished, so far as I know, but it has been approached in the experimental work in malaria control in Bolivar County, Mississippi, and especially in the demonstration made in Sunflower County, Mississippi, in 1918. These figures refer to all persons who have malaria. whether they are treated by physicians or whether they treat themselves. Since it appears that disinfection of all infected persons would result in complete elimination of the disease, it will be interesting to inquire what effect would follow the disinfection of all cases of malaria treated by physicians only. The extent to which the disease would be reduced, as a result of all physicians disinfecting all the cases they treat, would depend very largely upon the proportion of cases of malaria in a given locality that are treated by physicians. As is well known, a large proportion are not treated by them.

\section{PROPORTION OF ALL PERSONS INFECTED WITH MALARIA TREATED FOR IT BY PHYSICIANS}

In a study of 31,459 persons in Bolivar County in 1916 and 1917, the total numlber of persons who gave definite histories of previous attacks of malaria and those who gave negative histories but were found upon subsequent microscopical examination to have malaria parasites in their blood, when used as a basis of calculation and in comparison with the number of cases of malaria reported by physicians of the county as being treated by them, indicates that approximately onefifth of all the infected persons are treated for malaria by the doctors of Bolivar County. During 1918 a survey was made of 8,053 persons living in an area of one hundred square miles in Sunflower. County. The history of recent attacks. and blood examination of those who gave negative histories, indicated that approxi- mately $50 \%$ of the population have malaria during a year.

The reports of the physicians of Sunflower County made to the State Board of Health averaged 8,236 per year during the past five years. The population of the entire county is approximately sixtythree thousand. Basing our calculation upon the estimated number of persons who have malaria in the County and the actual number reported as treated by physicians of the County, it appears that the number of cases of malaria treated each year by physicians is approximately onefourth, or $25^{\prime}$ ', of the number of persons in the County who have malaria. We have, therefore, as a basis upon which to discuss the importance and possible results of disinfecting all cases treated by the physicians, the fairly definite information that approximately one-fifth in Bolivar County to one-fourth in Sunflower County of all persons who have malaria during the year are treated by physicians. Therefore, whatever results would follow would effect especially this fraction of the total number of persons who have malaria. Let us assume that one-fifth, or $20 \%$, is more nearly the correct proportion treated by physicians.

\section{RESULTS THAT WOULD FOLLOW DISINFHC- TION OF ALL CASES TREATED BY PHYSICIANS}

If $20 \%$ of the cases of malaria were disinfected during a given year, it would reduce the cases of relapse that woukd occur during the following year $20 \%$, which would represent $10 \%$ of the total amount of malaria that would otherwise be expected to occur. Not only would it do that, but it would also reduce the chances of transmission and occurrence of new cases to the same extent, or approximately $10 \%$ of the total number of cases that would otherwise occur. It would appear. therefore that if all doctors in a given locality disinfected all of their patients by efficient treatment, there would be a reduction of $20 \%$ in the total amount of malaria each year. For example. if that should be done during the present year. there should occur only 80 : as much malaria in 1920 as there would otherwise occur. During 1921 there would be a reduc- 
tion of $20 \%$ on the expected $80 \%$, or an incidence of $64 \%$ of what would have occurred if no cases were disinfected. During 1922 there would occur only $80 \%$ of the expected $64 \%$ of the present prevalence, which would be $51.20 \%$. It would appear, therefore, that it would take about four years to reduce the prevalence $50 \%$ if the physicians disinfected all of their malaria. This would be a large reduction and is an indication of what the medical profession could contribute to the control of malaria in this State in a comparatively short time.

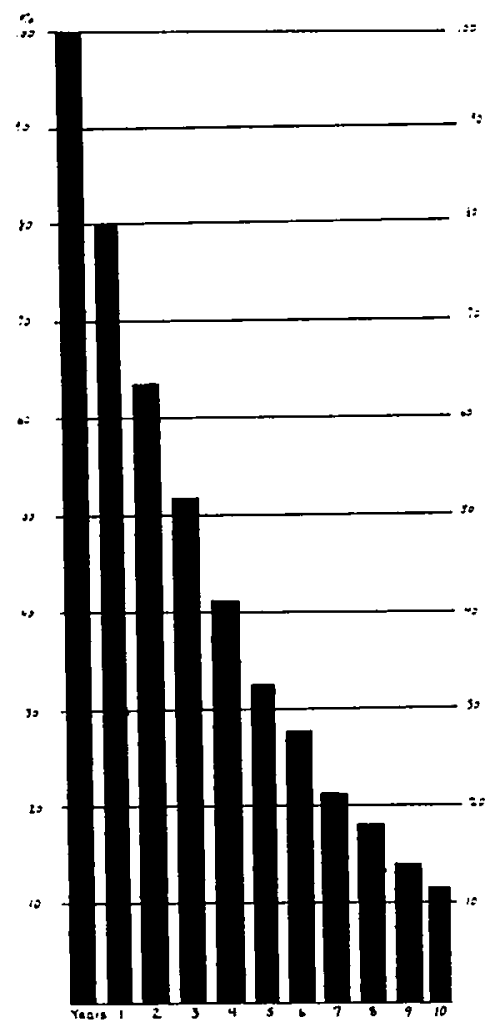

Chart 1.-Reduction of the amount of malaria that would result from disinfection of all cases treated by physicians.
WHY DOCTORS DO NOT DISINFECT THEIR MAIARIA CASES

If the possibilities along this line are as great as they seem to be, and if the matter is as important as we believe it is, it will be interesting and perhaps valuable to discuss briefly some of the reasons why doctors do not disinfect their malaria cases. I believe the most important contributing causes may be put down under one of three heads.

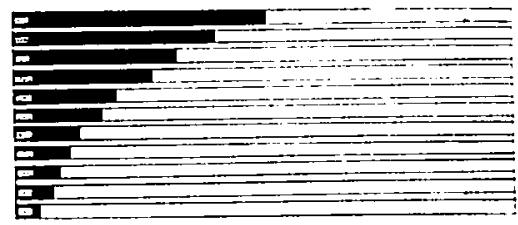

Chart 2.-The effect upon the prevalence of malaria that would be produced in Bolivar and Sunflower Counties in ten years if all doctors disinfected all persons treated by them who have malaria.

1. Spectacular Methods of Treatment. There seems to be a natural human weakness which effects doctors as well as other classes of people by which they are led to adopt and employ spectacular methods of treatment, forgetting or neglecting the tried, established and less spectacular methods. For instance, many doctors all over the country give quinin by deep injection when they know or could know that as good or better results would follow administration by mouth. Lately they have taken to administering quinin intravenously for ordinary cases of malaria when proper investigation would show them conclusively to their satisfaction that it is impractical, to say the least, to disinfect anybody in this way.

When patients come complaining that they can not take quinin, largely because of their own imagination, often encouraged by doctors, they give the patient still further encouragement that he can not take quinin, and give it, therefore, by deep injection or intravenously, or give some special salt or some special form which they can, by suggestion, make the patient think does not have the unpleasant effect that ordinary quinin sulphate does. My 
opinion is that it would be much better not to mislead the patient in this way nor ourselves, but to frankly advise him that he can and should go ahead and take quinin in the usual and simplest way. Women are especially likely to adopt the suggestion that they can not take quinin. Some of them seem to take great pleasure in considering themselves exceptional instances who have to have their quinin given in some special way and who can not take it like other people. The more we encourage these ideas, the more people we will find who imagine they can not take quinin.

As a matter of fact, practically all persons can take quinin without any great amount of inconvenience or discomfort. It is true that sometimes a considerable amount of discomfort is produced, but the discomfort is nothing like the discomfort produced by malaria, and usually it subsides in a short time. Those who wish to disinfect their patients must abandon their spectacular methods of treatment. and their special prescriptions and forms of quinin. Those who continue with such methods will have tew actual cures of malaria to their credit, whereas those who give quinin in sullicient doses for sufficient length of time will disinfect all of their cases. Anybody who is skeptical about the correctness of this statement can confirm it for himself if he will just carefully follow a few cases properly treated. Regardless of any inefliciency of quinin given by injection, the discomfort produced and the impracticability of continuing it long enough to disinfect malaria patients is sufficient argument against its use except perhaps in extremely rare cases.

2. Not Giving Patients Convincing Advice as to Treatment.-It often occurs that following the relief of acute clinical manifestations of malaria the doctor advises the patient to take quinin for a variable length of time. Sometimes the length of time is specified and it may be sufficiently long to disinfect the patient. Unfortunately, the advice is usually given in such a way as not to convince the patient of the necessity of it. He usually does not understand that he still has malaria parasites in him after all symptoms of the dis- ease have disappeared and that the continued use of quinin is necessary to disinfect him and prevent relapse. It is not necessary to tell the patient that quinin will not be inconvenient for him to take and will not produce any discomfort. It is more important to explain to him that quinin is the only remedy that will disinfect him and that it will do so only provided it is taken right for a sufticient length of time. If he is one who is especially susceptible to the unpleasant effects of quinin he is unfortunate, but this is no argument against its use if he has malaria.

Many cases get rid of their parasites on less treatment than others, but I believe that the minimum duration of treatment for all cases should be eight weeks. This will disinfect more than $90 \%$ of cases. It will do it. however, only provided the dose employed is sufliciently large. Fortunately, it is not necessary that it should exceed more than about ten grains a day for adults and a proportionate dose for children. If we wish to disinfect our patients, therefore, we must advise them in a way to convince them of the necessity of taking treatment for a suflicient length of time. It must be an extremely diflicult patient to reach if a doctor in whom he places confidence can not explain to him convineingly what malaria is and the necessity of carrying out proper treatment to prevent relapse and the transmission of the infection to others.

3. Not Employing Efficient Treatment. Another source of failure to disinfect malaria cases is the use of ineflicient treatment. Though quinin is a specific for malaria and will cure all cases, it will not do so unless the dose is sufficiently large and unless it is taken for a sufficient length of time. The common practice amongst those who treat malaria over this country is to give quinin for a few days followed by some preparation of quinin and perhaps arsenic and other drugs. The dose of quinin is insufficient to destroy parasites and disinfect the individual, and even though he stuck to the treatment as long as advised he would still fail to be disinfected. We should recognize that no tonics or other drugs have any specific action in the destruction of mala- 
ria parasites and that if employed at all they should not be allowed to take the place of the necessary amount of quinin nor should the dose of quinin be reduced to below what is necessary to destroy parasites. Generally it is much better not to give anything besides quinin to malaria patients following acute attacks.

\section{SUMMARY}

1. It is important to disinfect persons treated for malaria for their own benefit to prevent relapse, and also to remove the source of infection to others.

2 . If all cases of malaria treated by physicians were disinfected by the treatment, it would result in rapid decline of the prevalence of the disease. It would reduce the prevalence of malaria about. $90 \%$ in ten years.

3 . The chief causes of failure at the present time are believed to be, (a) spectacular methods of treatment, (b) not giving patients convincing advice as to the mature of the disease and necessity for proper treatment, and (c) not advising eflicient treatment.

\section{REFERESCES}

1. Harris, Seale: Prevention of Malaria. Jour. A. II. A., October, 1909, Vol. 53, pp. 1162-1165.

$\because$. Henson, Graham E.: Man, the Principal Etiologic Factor in the Perpetuation of Malaria, with Special Reference to the Endemicity of the Disease in the Temperate Zone. Jour. A. M. A., May 2, 1914, Vol. 62, No. 18, pp. 1374-1377.

3. Osler Anniversary Volume, 1919, Paul B. Hoeber, 69 E. 5th Ave., New York, publisher.

\section{REPORT OF A STATE HEALTH OFFICER*}

BY S. W. WELCH, M.D.,

Health Officer, State of Alabama, Montgomery, Ala.

The events which have transpired since the writer's last report have been less spectacular than in the preceding year, but have been of no less far-reaching importance to the people of the State of Alabama.

After a careful study of the public heaith problems confronting the citizens of Alabama, the conclusion was reached that a business organization with the unit of operation corresponding with the po-

\footnotetext{
"Read before the Alabama State Medical Association, Mobile, April 15, 1919.
}

litical unit was the first step to be taken. Observation of the results in counties where all-time health officers had been established without sufficient means to employ assistants, disclosed the fact that we had expected too much of the system which provided all-time health officers. The conclusion was reached that we would recommend to each county that a sufficient appropriation be made to supply a minimum personnel of a health officer, a rural nurse, a rural inspector and some one to keep the office and make microscopical examinations. We have to report, in addition to the counties of Walker, Tuscaloosa, Elmore, Jefferson, Talladega, Madison, Choctaw and Pickens, that Lauderdale, Mobile, Calhoun and Montgomery have adiopted the alltime health officer system and have made appropriations sufficient for the support of an organization. Five other counties are being organized under a cooperative arrangement wi h the International Health Board, under the supervision of a Field Director. It is contemplated to build a health organization in each of these counties, turning it over to the local authorities as soon as it is capable of independent function.

It is proposed to put another man over five other counties in a similar work as soon as money can be obtained from the l.egislature to finance it. The International Health Board has advanced the money to the State Board of Health to operate the first five months, on reliable assurance that the State would assume its part of the burden in July, 1919.

During the summer of 1918, Congress appropriated $\$ 1,000,000$ for state aid in the control of venereal diseases. Alabama's share of the appropriation was $\$ 23,247.15$. The appropriation was made contingent upon the State's putting up a like amount, but was immediately available for Alabama, pending the neeting of the Legislature. Mr. Blasingame was elected by the Board as Field Representative. He represents the U. S. Public Health Service in the work, but is per se a member of the force of the State Board of Health.

The work of organizing venereal clinics has gone on as rapidly as is consistent with stability. Mr. Blasingame is a tire- 